\title{
COMUNICAÇÃO
}

\section{AVALIAÇÃO DE CARACTERÍSTICAS DA CARCAÇA E DA QUALIDADE DA CARNE DE QUEIXADA (Tayassu pecari [Link, 1795])}

\author{
Evaluation of carcass characteristics and meat quality of white-lipped peccary \\ (Tayassu pecari [Link, 1795])
}

\author{
Eduardo Mendes Ramos ${ }^{1}$, Cristiane Patrícia de Oliveira ${ }^{2}$, Rosali Amaral Matos ${ }^{3}$, \\ Carine Menezes Mota ${ }^{4}$, Dimas Oliveira Santos ${ }^{5}$
}

\begin{abstract}
RESUMO
No presente trabalho, propôs-se avaliar os parâmetros de qualidade na carcaça e carne de queixadas adultas. Um total de quatro queixadas (três machos e uma fêmea), com peso vivo (PV) médio de $29,47 \pm 3,45 \mathrm{~kg}$, foi abatido, determinado o rendimento de carcaça quente (RCQ), e avaliada a área do olho do lombo (AOL), gordura de marmoreio (GM), espessura da gordura de cobertura (EGC), $\mathrm{pH}$, perda de peso por cozimento (PPC), concentração de pigmentos heme totais (PHT) e composição centesimal no músculo Longissimus dorsi (LD). O RCQ em relação ao PV foi de 53,80\%, assemelhando-se aos índices observados em bovinos e búfalos, sendo encontrada uma quebra de peso de 3,22\% após refrigeração. O pH médio final, após 24 horas, foi de 5,54, dentro da faixa considerada normal para carnes suínas. Os valores médios obtidos para AOL $\left(14,44 \mathrm{~cm}^{2}\right)$ e EGC $(3,75 \mathrm{~mm})$ indicam um bom desenvolvimento muscular e uma menor proporção de gordura na carcaça, também evidenciada pela existência de traços de GM e pelo baixo conteúdo de lipídeos observados no lombo. De forma geral, o lombo apresentou composição média de 74,59\% de umidade, $20,25 \%$ de proteína, $1,08 \%$ de lipídeos e $1,17 \%$ de cinzas, muito similares aos observados em animais convencionais. Os dados médios de PHT $(69,49$ ppm) e PPC $(13,68 \%)$ demonstram a qualidade da carne de queixada, uma vez que refletem no favorecimento da cor vermelha do produto final e em uma baixa perda de peso do corte, durante o preparo.
\end{abstract}

Termos para indexação: Composição química, pigmentos heme, rendimento de carcaça.

\section{ABSTRACT}

This work was carried out to evaluate carcass and meat quality attributes of adult white-lipped peccaries. A total of four white-lipped peccaries (three males and one female), with average of live weights (LW) of $29.47 \pm 3.45 \mathrm{~kg}$, were slaughtered and evaluated for hot carcass dressing (HCD), ribeye area (REA), rib fat thickness (RFT), intramuscular fat (marbling), $\mathrm{pH}$, cook loss (CL), total haem pigments (THP) and proximate composition of Longissimus dorsi (LD). The HCD in relation to LW was of 53.80\% and a shrink loss of $3.22 \%$ after 24 hours of refrigeration was found. The final $\mathrm{pH}$ (5.54) observed was considered normal for pork carcass. The REA $\left(14.44 \mathrm{~cm}^{2}\right)$ and RFT $(3,75 \mathrm{~mm})$ values indicate a good muscular development and a low proportion of fat in the carcass, also evidenced for marbling traces and low content of lipids observed in the LD. The loin proximate composition was: $74.59 \%$ of moisture; $20.25 \%$ of protein; $1.08 \%$ of ethereal extract; and $1.17 \%$ of ash. The THP $(69.49 \mathrm{ppm})$ and CL (13.68\%) values show the meat quality of the peccaries, since the THP are related to the red color of the meat and CL indicates a low loss of weight during cooking.

Index terms: Carcass yield, haem pigments, proximate composition.

(Recebido em 5 de dezembro de 2006 e aprovado em 19 de março de 2008)

Embora atualmente a produção de carnes se encontre concentrada na exploração de bovinos, suínos e aves, há um grande interesse social na disponibilização de novas fontes protéicas, especialmente a oriunda da fauna silvestre, uma vez que, além de oferecer novos produtos ao mercado, resultando em vantagens econômicas e sociais, protege tais espécies da extinção.

A criação de animais em cativeiro permite a utilização da fauna silvestre de forma racional, gerando fontes renováveis de produtos de grande rentabilidade,

\footnotetext{
${ }^{1}$ Engenheiro de Alimentos, Doutor em Ciência e Tecnologia de Alimentos, Professor Adjunto - Departamento de Ciência de Alimentos/DCA - Universidade Federal de Lavras/UFLA - Cx. P. 3037 - 37200-000 - Lavras, MG - emramos@ufla.br

²Engenheiro de Alimentos, Mestre em Ciência e Tecnologia de Alimentos, Professora Assistente - Departamento de Tecnologia Rural e Animal/DTRA Universidade Estadual do Sudoeste da Bahia/UESB - Praça Primavera, 40 - Primavera - 45700-000 - Itapetinga, BA - cpoliveira@uesb.br ${ }^{3}$ Engenheira de Alimentos - Rua Tiradentes, 56 - Centro - 45200-000 - Jequié, BA - zalarama@hotmail.com ${ }^{4}$ Engenheiro de Alimentos - Rua João Ottoni Oliveira, 17 - Centro - 45545-000 - Ubaitaba, BA - carinemenezes@bol.com.br 5Zootecnista, Mestre em Zootecnia - Departamento de Tecnologia Rural e Animal/DTRA - Universidade Estadual do Sudoeste da Bahia/UESB - Praça Primavera, 40 - Primavera - 45700-000 - Itapetinga, BA - dimas@uesb.br
} 
contribuindo para a produção de alimentos e concorrendo em custo de produção com os animais domésticos (ODA et al., 2004). Nesse contexto, o queixada (Tayassu pecari [LINK, 1795]) se apresenta como uma espécie com grande potencial zootécnico para a produção de carne.

Os queixadas pertencem à Família Tayassuidae, encontrados exclusivamente no Continente Americano, embora tenham habitado a Europa e a Ásia, onde se separaram da Família Suidae, a qual pertence o porco doméstico (NOGUEIRA FILHO, 1990). De pelagem marrom avermelhada a preta com estrias esbranquiçadas, apresentando um colar de pêlos brancos, que se estende desde a frente da paleta até a crina na região dorsal, o queixada apresenta um comprimento que varia de 1,10 a 1,19 metros e um peso vivo de aproximadamente $40 \mathrm{Kg}$ para animais adultos (SOWLS, 1984).

Atualmente, o mercado consumidor tem se mostrado bastante receptivo ao consumo de carne de animais silvestres e exóticos (ODA et al., 2004). Frente a essa crescente demanda, tanto no mercado interno quanto no externo, e frente à nova legislação de produtos alimentícios, que exige grande quantidade de informações nutricionais, tornam-se necessários estudos que descrevam esse produto.

Objetivou-se, neste trabalho, obter informações preliminares das características da carcaça e qualidade da carne de queixadas adultos criados em cativeiro. Os animais utilizados nesse experimento foram criados no Criatório Comercial de Queixadas da Universidade Estadual do Sudoeste da Bahia (UESB), sendo alimentados por capim, forragens e ração concentrada com $13 \%$ de proteína bruta e $2.800 \mathrm{kcal} / \mathrm{kg}$.

Quatro queixadas (três machos e uma fêmea), com idade média de 13 meses e peso vivo (PV) médio de 29,47 \pm $3,45 \mathrm{~kg}$, foram abatidos, sem jejum prévio, no abatedouro da Unidade Experimental de Caprinos e Ovinos (UECO/UESB). Os animais, presos por laços (cambão) de captura, foram conduzidos à sala de abate e submetidos à insensibilização elétrica preconizada para suínos. Os animais foram previamente molhados para facilitar a passagem da corrente elétrica, sendo os eletrodos do insensibilizador (Sulmaq, Modelo 7654) posicionados atrás das orelhas e uma voltagem de 300 volts aplicada por cerca de 5 segundos (BENEVENUTO JÚNIOR, 2001). A sangria foi realizada imediatamente, entre 5 a 10 segundos, após a insensibilização.

Depois de sangrados, os animais sofreram os processos de esfola, com remoção da pele, evisceração e remoção da cabeça. As carcaças foram, então, pesadas (peso da carcaça quente - PCQ), dependuradas pela articulação tarso metatarsiana e conduzidas à câmara de refrigeração, onde permaneceram por 24 horas, a uma temperatura média de $2^{\circ} \mathrm{C}$.
As carcaças resfriadas foram novamente pesadas (peso da carcaça fria - PCF) e serradas longitudinalmente, sendo as meias-carcaças desossadas realizando-se os cortes comerciais preconizados para ovinos (SILVA, 2005). Devido à forma de obtenção dos cortes comerciais (cortes transversais no lombo, entre a $1^{\mathrm{a}}$ e $13^{\mathrm{a}}$ vértebra torácica, são feitos para obtenção do carré), a área de olho de lombo (AOL), medida no músculo Longissimus dorsi (LD), foi obtida entre a $12^{\mathrm{a}}$ e $13^{\mathrm{a}}$ costela (Figura 1) e não entre a $10^{\mathrm{a}}$ e $11^{\mathrm{a}}$ costela, conforme preconizado para suínos, pela National Pork Production Council (NPPC) (GOMIDE et al., 2006).

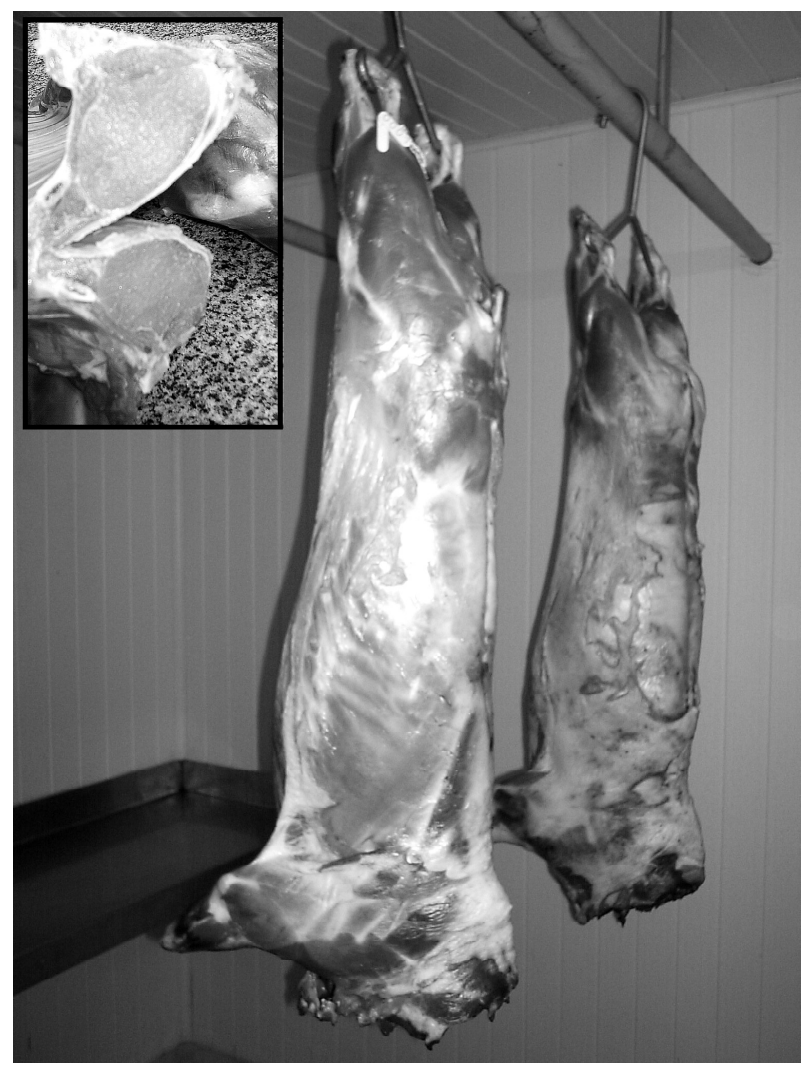

Figura 1 - Carcaças resfriadas de queixadas. Em detalhe, corte transversal entre a $12^{\mathrm{a}}$ e $13^{\mathrm{a}}$ costela, para exposição do lombo (Longissimus dorsi).

O contorno do perímetro do músculo LD, exposto no carré, foi obtido com a utilização de papel vegetal e a área determinada $\left(\mathrm{em}^{2} \mathrm{~cm}^{2}\right)$ por integração mássica, obtida recortando-se o gráfico, pesando-o em balança analítica e comparando-o com o peso da área unitária. Também foi medida a espessura da gordura de cobertura (EGC) na linha 
dorso-lombar do corte, a 3/4 do seu comprimento maior, com o auxílio de um paquímetro. Ainda no músculo exposto, foi estimado o grau de marmoreio, fazendo-se uso da escala proposta pela NPPC, segundo Gomide et al. (2006).

Do músculo LD desossado foram obtidas amostras para as análises, em triplicata, do $\mathrm{pH} 24$ horas $\left(\mathrm{pH}_{\mathrm{u}}\right)$, pela homogeneização em água destilada (TERRA \& BRUM, 1988), pigmentos heme totais (PHT), pelo método de Hornsey (1956), e perda por cozimento (PPC), segundo método de Honikel (1998). Amostras do músculo LD também foram retiradas para análise centesimal, sendo feitas, segundo metodologia oficial da Secretaria de Defesa Agropecuária (BRASIL, 1999), as determinações: umidade, pelo método de estufa a $105^{\circ} \mathrm{C}$; resíduo mineral fixo (cinzas), pelo uso de mufla a $550^{\circ} \mathrm{C}$; proteínas, pelo método de microKjeldahl; e lipídios, pelo método do butirômetro de leite. A análise centesimal também foi conduzida em triplicata.

As características de rendimento avaliadas foram determinadas da seguinte forma:

- rendimento de carcaça quente $(\mathrm{RCQ})=100 \mathrm{x}$ peso da carcaça quente (PCQ) / peso vivo (PV);

- quebra de peso durante a refrigeração $(\mathrm{QPR})=$ $100 \times$ [peso da carcaça quente (PCQ) - peso da carcaça fria $(\mathrm{PCF})]$ / peso da carcaça quente (PCQ).

Na Tabela 1, encontram-se os valores médios dos parâmetros quantitativos avaliados.

O valor médio de $53,80 \%$ para o rendimento de carcaça quente (RCQ) foi semelhante aos valores observados (entre 52,10 a 60,56\%), para búfalos e bovinos nelores e cruzas (RODRIGUEZ et al., 2003), mas superior aos 42,59 a 48,83\% observados para ovinos (MONTEIRO et al., 2001; SILVA, 2005) e aos 49,80 e 51,60\% observados para capivaras (ALBUQUERQUE, 1993; BRESSAN et al., 2002). No entanto, os valores de RCQ dos queixadas se encontra abaixo dos 58,79\%, observado por Silva et al. (2002) para catetos (Tayassu tajacu), com $17 \mathrm{~kg}$ de peso vivo e alimentação com $14 \%$ de proteína bruta e $3.300 \mathrm{kcal} /$ $\mathrm{kg}$, e muito abaixo das médias de 74,69 a 82,29\%, relatados por Villarreal (1996) para suínos.

A quebra de peso média das carcaças, oriunda da perda de água por gotejamento ou evaporação, foi de 3,22\%, acima dos 2,0 a 2,4\% considerados normais em processos convencionais de refrigeração (GOMIDE et al., 2006). Essa maior perda de peso, durante a refrigeração, pode ser oriunda da menor proporção de gordura subcutânea na carcaça dos queixadas, especialmente na região traseira (Figura 1), o que implica numa maior razão superfície/volume e, conseqüentemente, em perdas excessivas por evaporação (SAVELL et al., 2004). A baixa quantidade de gordura subcutânea na carcaça, também acarreta na maior propensão dela ao fenômeno do encolhimento pelo frio (GOMIDE et al., 2006), o que pode gerar um encurtamento muscular e conseqüente aumento da perda de água por gotejamento.

No post mortem ocorre o acúmulo de ácido lático, responsável pela acidificação do músculo e a conseqüente redução do $\mathrm{pH}$. O controle do $\mathrm{pH}$ é de fundamental importância para avaliar a qualidade da carne, uma vez que influencia vários aspectos de qualidade, como, por exemplo, capacidade de retenção de água (CRA), perda de peso por cozimento (PPC) e propriedades sensoriais como suculência, maciez, sabor e cor (LAWRIE, 2005). O pH final $\left(\mathrm{pH}_{\mathrm{u}}\right)$ da carne de queixadas, obtido após 24 horas de refrigeração, encontra-se na faixa considerada normal (entre 5,40 e 5,70), considerada típica para a carne de suínos (KAUFFMAN, 1991).

A média da área do olho do lombo (AOL) observada foi de $14,44 \mathrm{~cm}^{2}$, próximo da faixa de 9,18 a $11,45 \mathrm{~cm}^{2}$ reportados por (GARCIA, 1998), para ovinos abatidos com peso vivo próximo de $30 \mathrm{~kg}$, e dos $14,15 \mathrm{~cm}^{2}$, relatados por Monteiro et al. (2001), também para ovinos, porém com peso vivo próximo de $40 \mathrm{~kg}$. Isso demonstra um bom

Tabela 1 - Médias e desvio padrão (DP) dos parâmetros quantitativos da carcaça e carne de queixadas.

\begin{tabular}{lcc}
\multicolumn{1}{c}{ Parâmetro } & Média & DP \\
\hline Peso vivo ao abate $-\mathrm{PV}(\mathrm{Kg})$ & 29,47 & 3,45 \\
Peso carcaça quente - CQ $(\mathrm{Kg})$ & 15,94 & 2,92 \\
Rendimento da CQ $(\%)$ & 53,80 & 3,90 \\
Peso carcaça fria - CF $(\mathrm{Kg})$ & 15,43 & 2,95 \\
Quebra de peso na refrigeração $(\%)$ & 3,22 & 1,19 \\
pH final $\left(\mathrm{pH}{ }_{\mathrm{u}}\right)$ & 5,54 & 0,27 \\
Área do olho de lombo - AOL $\left(\mathrm{cm}^{2}\right)$ & 14,44 & 2,35 \\
Espessura da gordura de cobertura - EGC $(\mathrm{mm})$ & 3,75 & 2,06 \\
Marmoreio (padrão NPPC) & 2 (traços) & - \\
\hline
\end{tabular}


desenvolvimento de massa muscular na região lombar de queixadas adultos, o que corresponde a uma região considerada de corte nobre.

No entanto, a AOL de queixadas foi bem menor do que os $35,53 \mathrm{~cm}^{2}$, observado por (BRESSAN et al., 2002) para capivaras, com peso vivo médio de $62 \mathrm{~kg}$, e dos 31,99 $\mathrm{cm}^{2}$, reportados por (FREITAS et al., 2004) para suínos com peso ao abate de $95 \mathrm{~kg}$. Em bovinos, a AOL é da ordem de $73,77 \mathrm{~cm}^{2}$, para animais com peso vivo médio de $400 \mathrm{~kg}$, e 84,22 $\mathrm{cm}^{2}$, para animais com peso vivo de $480 \mathrm{~kg}$ (CRUZ et al., 2001). Essa diferença é esperada, devido ao menor porte do queixada, uma vez que a AOL está intimamente associada ao tecido muscular do animal, sendo que, à medida que essa característica aumenta, a taxa de músculos dos cortes nobres também aumenta (GOMIDE et al., 2006).

Vale ainda ressaltar que, embora os animais tenham sido criados em cativeiro, eles foram submetidos a uma dieta não-específica, devido à escassez de estudos zootécnicos, para a criação de queixadas. Uma vez que a dieta é um fator determinante no crescimento e desenvolvimento muscular e na deposição de gordura na carcaça (LAWRIE, 2005), é de se esperar que, com a realização de estudos zootécnicos e definição da dieta adequada para esses animais, os índices de rendimento, musculosidade e acabamento (teor de gordura subcutânea) possam ser consideravelmente melhorados.

A espessura da gordura de cobertura (EGC), observada nos queixadas $(3,75 \mathrm{~mm})$, foi bem menor do que os 35,39 mm reportados para suínos (FREITAS et al., 2004). Essa menor EGC, comparada a de suínos, é devido tanto à menor deposição de gordura subcutânea pelos queixadas quanto à etapa de esfola, onde o couro é completamente removido. Embora tenha havido uma grande variação nesses valores, os animais apresentaram uma camada de gordura subcutânea considerável, superior aos 1,13 mm reportados para ovinos (MONTEIRO et al., 2001) e próximo dos valores de 2,2 a 3,3 mm relatados para bovinos (CRUZ et al., 2001).

A EGC é um indicador real do conteúdo de gordura da carcaça, que se relacionada negativamente com a porcentagem de músculo da carcaça (GOMIDE et al., 2006). Segundo Jardim et al. (1985), para cada incremento na unidade de medida da espessura de gordura subcutânea há uma redução de $1,08 \%$ na porcentagem de músculo e um aumento de $1,74 \%$ na porcentagem de gordura da carcaça.

Apesar da redução no teor de gordura da carcaça ir ao encontro da procura do consumidor por carnes mais magras, uma camada de gordura de cobertura, associada a quantidades apreciáveis de gordura de marmoreio, são fatores que interferem favoravelmente na maciez da carne, especialmente na percepção da sua suculência (GOMIDE et al., 2006). Segundo Wood (1990), para uma ótima maciez e suculência, considerando o músculo LD de bovinos e ovinos, a porcentagem de lipídeos intramuscular deve situar-se próximo de 2 a 3\%. Em suínos, os valores limites de qualidade sugeridos pela NPPC para o teor de lipídeos intramuscular no músculo LD é de 2 e $4 \%$, faixa acima dos $1,08 \%$ observados para queixadas (Tabela 2 ).

Tabela 2 - Valores médios da composição química, pigmentos heme totais (PHT) e perdas por cozimento (PPC) de músculos Longissimus dorsi de queixadas.

\begin{tabular}{lc}
\hline \multicolumn{1}{c}{ Variáveis } & Valores médios \\
\hline Umidade (\%) & 74,59 \\
Proteína (\%) & 20,25 \\
Gordura (\%) & 1,08 \\
Cinzas (\%) & 1,17 \\
Pigmentos heme totais - PHT (ppm) & 69,48 \\
Perda por cozimento - PPC (\%) & 13,96 \\
\hline
\end{tabular}

De forma geral, a composição centesimal do lombo de queixadas se assemelha à observada em capivaras (ODA et al., 2004) e outros animais convencionais, como bovinos, ovinos e suínos. Apenas a gordura (no caso a intramuscular do LD) difere dos valores de 3,17 a 13,30\% observados em ovinos (MONTEIRO et al., 2001; PEREZ et al., 2002) e de 3,0\% em suínos (BRAGAGNOLO, 1997; LATORRE et al., 2004). Essa diferença no porcentual de lipídeos pode ser devido a diferenças na espécie, dieta, sistema de criação, idade e/ou peso dos animais.

Para catetos, Silva et al. (2002) encontraram um o teor de gordura médio de $8,50 \%$, muito acima dos valores observados $(1,08 \%)$ para queixadas nesse experimento. No entanto, além das possíveis causas citadas no parágrafo anterior, essa diferença também pode ser devido ao tipo de músculo analisado, uma vez que os autores não deixaram claro em que músculo foi avaliada a composição centesimal dos catetos.

Os valores de pigmentos heme totais (PHT) observados no músculo LD de queixadas (69,48 ppm) se encontram entre a faixa de 24,36 e 31,07 ppm, reportados para suínos (LATORRE et al., 2004), e o valor médio de 168,03 ppm, reportado por Monteiro et al. (2001) para ovinos. A concentração de mioglobina no músculo varia segundo a espécie animal, sendo muito maior em bovinos 
e ovinos do que em suínos e aves. Essa diferença entre espécies é oriunda das diferenças no tipo predominante de fibra muscular, o que se reflete no grau de atividade física diferenciado entre elas (LAWRIE, 2005). Assim, era de se esperar que músculos de queixadas apresentassem uma maior quantidade de mioglobina do que suínos, uma vez que os primeiros, por não serem domesticados, possuem uma atividade muscular muito mais intensa do que os últimos. Essa maior concentração de pigmentos heme observada em queixadas, em relação aos suínos, favorece a cor vermelha da carne, um parâmetro extremamente importante tanto para a sua comercialização in natura, quanto para o seu processamento.

Por fim, a perda por cozimento (PPC) do lombo de queixadas $(13,96 \%)$ foi inferior ao reportado na literatura para animais convencionais e silvestres. Em bovinos adultos, Lesiów \& Ockerman (1998) encontraram valores entre 38,23 e 40,48\%. Bressan et al. (2001), estudando músculos LD de ovinos abatidos com 15 a $45 \mathrm{~kg}$ de peso vivo, citaram valores de 27,6 a 33,10\%, enquanto Monteiro et al. (2001) relataram valores de $17,78 \%$ para ovinos com peso vivo de $42 \mathrm{~kg}$. Em suínos, Silveira (1997) citou valores entre 27,17 a 36,62\%, enquanto Latorre et al. (2004) encontraram médias entre 17,3 e 19,4\%. Para capivara, os valores de PCC variam de 24,93 a 33,84\% (BRESSAN et al., 2004; ODA et al., 2004).

A PPC está associada ao rendimento da carne no momento do consumo, tendo sido constatada sua forte relação com a gordura presente, como no trabalho de Schönfeldt et al. (1993) que relataram que animais com maiores teores de gordura apresentavam maior PPC. Embora outros fatores, como metodologias de cocção e preparo da amostra, possam ter contribuído para as diferenças observadas entre a carne de queixadas e as demais espécies, não se pode desconsiderar o baixo valor de PPC encontrado, que se reflete na menor perda de peso (tamanho) durante o preparo e, possivelmente, no favorecimento da maciez da carne (maior suculência, devido à menor perda de água e gordura).

Os resultados obtidos nesse experimento evidenciaram o potencial para comercialização da carne de queixadas, que apresentou padrões de qualidade próximos dos exigidos no mercado consumidor. No entanto, além de estudos zootécnicos para otimizar a criação desses animais, faz-se necessário um estudo mais abrangente da qualidade da carne, com maior número de animais criados para esse fim, avaliando-se, ainda, características que permitam estimar o uso em potencial dessa carne na elaboração de produtos cárneos derivados.

\section{REFERÊNCIAS BIBLIOGRÁFICAS}

ALBUQUERQUE, N. I. Ganho de peso em capivaras (Hydrochoerus hydrochaeris hydrochaeris L. 1766) na fase final de crescimento em 3 categorias: machos inteiros, machos castrados e fêmeas. 1993. $65 \mathrm{f}$. Dissertação (Mestrado em Agronomia) - Escola Superior de Agricultura “Luiz de Queirós”, Piracicaba, 1993.

BENEVENUTO JÚNIOR, A. A. Avaliação de rendimentos de carcaça e qualidade da carne de suínos comerciais, de raça nativa e cruzados. 2001.99 f. Dissertação (Mestrado em Ciência e Tecnologia de Alimentos) Universidade Federal de Viçosa, Viçosa, 2001.

BRAGAGNOLO, N. Fatores que influenciam o nível de colesterol, lipídeos totais e composição de ácidos graxos em camarão e carne. 1997. 123 f. Tese (Doutorado em Ciência de Alimentos) - Universidade Estadual de Campinas, Campinas, 1997.

BRASIL. Ministério da Agricultura, Pecuária e Abastecimento. Secretaria de Defesa Agropecuária. Instrução Normativa n. 20, de 21 de julho de 1999. Lex: Diário Oficial da União, Brasília, 27 jul. 1999. Seção 1.

BRESSAN, M. C.; JARDIM, N. S.; PEREZ, J. R. O.; THOMAZINI, M.; LEMOS, A. L. S. C.; ODA, S. H. I.; PISA, A. C. C.; VIEIRA, J. O.; FARIA, P. B.; FREITAS, R. T. F. Influência do sexo e faixas de peso ao abate nas características físico-químicas da carne de capivara.

Ciência e Tecnologia de Alimentos, Campinas, v. 24, n. 3, p. 357-362, 2004

BRESSAN, M. C.; MIGUEL, G. Z.; FARIA, P. B.; VIEIRA, J. O.; ODA, S. H. I. Rendimento de carcaça e de cortes comerciais de Capivaras (Hydrochoerus Hydrochaeris L.1766). Ciência e Agrotecnologia, Lavras, p. 1588-1593, 2002. Edição especial.

BRESSAN, M. C.; PRADO, O. V.; PÉREZ, J. R. O.; LEMOS, A. L. S. C.; BONAGURIO, S. Efeito do peso ao abate de cordeiros Santa Inês e Bergamácia sobre as características físico-químicas da carne. Ciência e Tecnologia de Alimentos, Campinas, v. 21, n. 3, p. 293303, 2001.

CRUZ, G. M.; TULLIO, R. R.; ALENCAR, M. M.; ESTEVES, S. N. Efeito do peso de abate sobre a qualidade de carcaça e o rendimento de cortes cárneos 
comerciais de bovinos jovens cruzados. In: CONGRESSO BRASILEIRO DE CIÊNCIA E TECNOLOGIA DE CARNES, 1., 2001, São Pedro. Anais... São Pedro: CTC/ITAL, 2001. p. 92-93.

FREITAS, R. T. F.; GONÇALVES, T. M.; OLIVEIRA, A. I. G.; FERREIRA, D. F. Avaliação de carcaças de suínos da Raça Large White utilizando medidas convencionais. Revista Brasileira de Zootecnia, Viçosa, v. 33, n. 6, p. 2037-2043, 2004. Suplemento 2.

GARCIA, C. A. Avaliação do resíduo de panificação "biscoito" na alimentação de ovinos e nas características quantitativas e qualitativas da carcaça. 1998. 79 f. Dissertação (Mestrado em Zootecnia) Universidade Estadual Paulista, Jaboticabal, 1998.

GOMIDE, L. A. M.; RAMOS, E. M.; FONTES, P. R. Tecnologia de abate e tipificação de carcaças. Viçosa: UFV, 2006. 370 p.

HONIKEL, K. O. Reference methods for the assessment of physical characteristics of meat. Meat Science, Oxford, v. 49, n. 4, p. 447-457, 1998.

HORNSEY, H. C. The colour of cooked cured pork: I estimation of the Nitric oxide-Haem pigments. Journal of the Science Food and Agriculture, London, v. 7, p. 534540, 1956.

JARDIM, P. O. C.; ZIEGLER, J. C. S.; OSÓRIO, J. C. S. Predição dos principais cortes da carcaça em novilhos. Pesquisa Agropecuária Brasileira, Brasília, v. 20, n. 2, p. 253-258, 1985.

KAUFFMAN, R. G. Electronic evaluation of meat quality. In: SYMPOSIUM ELECTRONIC EVALUATION OF MEAT IN SUPPORT OF VALUE-BASED MARKETING, 1991, Indiana. Proceedings... Indiana: Purdue University, 1991. p. 199-221.

LATORRE, M. A.; LÁZARO, R.; VALÊNCIA, D. G.; MEDEL, P.; MATEOS, G. G. The effects of gender and slaughter weight on the growth performance, carcass traits, and meat quality characteristics of heavy pigs. Journal of Animal Science, New York, v. 82, p. 526-533, 2004.

LAWRIE, R. A. Ciência da carne. 6. ed. São Paulo: Artmed. 2005. 384 p.
LESIÓW, T.; OCKERMAN, H. W. Funcional and sensory attributes of normal $\mathrm{pH}$ values in $\mathrm{Sm}$ e $\mathrm{Ld}$ of bull muscles depending on time of cutting and aging. In:

INTERNATIONAL CONGRESS OF MEAT SCIENCE AND TECHNOLOGY (ICoMST), 44., 1998, Barcelona. Anais... Barcelona: [s.n.], 1998.

MONTEIRO, E. M.; RUBENSAN, J.; PIRES, G. Avaliação de parâmetros de qualidade da carcaça e da carne de ovinos. In: CONGRESSO BRASILEIRO DE CIÊNCIA E TECNOLOGIA DE CARNES, 1., 2001, São Pedro. Anais... São Pedro: CTC/ITAL, 2001. p. 98-99.

NOGUEIRA FILHO, S. L. G. Estudo da digestibilidade de nutrientes em caitetus (Tayassu tajacu (L.) Wetzel, 1977) adultos submetidos a dietas com níveis crescentes de alimentos volumosos. 1990. $101 \mathrm{f}$. Dissertação (Mestrado em Agronomia) - Escola Superior de Agricultura “Luiz Queiroz”, Piracicaba, 1990.

ODA, S. H.; BRESSAN, M. C.; MIGUEL, G. Z.; VIEIRA, J. O.; FARIA, P. B.; SAVIAN, T. V.; KABEYA, D. M. Efeito do método de abate e do sexo sobre a qualidade da carne de capivara (Hydrochaeris hydrochareis). Ciência e Tecnologia de Alimentos, Campinas, v. 24, n. 3, p. 341346, 2004.

PEREZ, J. R. O.; BRESSAN, M. C.; BRAGAGNOLO, N.; PRADO, O. V.; LEMOS, A. L. S. C.; BONAGURIO, S. Efeito do peso ao abate de cordeiros Santa Inês e Bergamácia sobre o perfil de ácidos graxos, colesterol e propriedades químicas. Ciência e Tecnologia de Alimentos, Campinas, v. 22, n. 1, p. 11-18, 2002.

RODRIGUEZ, V. C.; ANDRADE, I. F.; FREITAS, R. T.; BRESSAN, M. C.; TEIXEIRA, J. C. Rendimentos do abate e carcaça de bovinos e bubalinos castrados e inteiros. Revista Brasileira de Zootecnia, Viçosa, v. 32, n. 3, p. 663-671, 2003.

SAVELL, J. W.; MUELLER, S. L.; BAIRD, B. E. The chilling of carcasses. In: INTERNATIONAL CONGRESS OF MEAT SCIENCE AND TECHNOLOGY, 50., 2004, Helsinki. Proceedings... Helsinki: [s.n.], 2004. p. 324-327.

SCHÖNFELDT, H. C.; NAUDÉ, R. T.; BOK, W.; HEERDEN, S. M. van; SOWDEN, L.; BOSHOFF, E. Cooking and juicinessrelated quality characteristics of goat and sheep and meat. Meat Science, Oxford, v. 34, p. 381-394, 1993. 
SILVA, A. M. P. Avaliação da carcaça, crescimento alométrico dos cortes e órgãos internos de cordeiros as raça Santa Inês em diferentes idades de abate. 2005. $57 \mathrm{f}$. Dissertação (Mestrado em Zootecnia) - Universidade Estadual do Sudoeste da Bahia, Itapetinga, 2005.

SILVA, F. N.; PINHEIRO, M. J. P.; BARROS NETO, F.; BRAGA, A. P. Características da carcaça e análise químicobromatológica da carne de catetos (Tayassu tajacu) submetidos a quatro níveis de proteína bruta em condições de cativeiro. Caatinga, Mossoró, v. 15, n. 1/2, p. 57-60, 2002

SILVEIRA, E. T. F. Técnicas de abate e seus efeitos na qualidade da carne suína. 1997. 226 f. Tese (Doutorado em Tecnologia de Alimentos) - Universidade Estadual de Campinas, Campinas, 1997.
SOWLS, L. K. The peccaries. Arizona: The University of Arizona, 1984. 251 p.

TERRA, N. N.; BRUM, M. A. R. Carnes e seus

derivados: técnicas de controle de qualidade. São Paulo: Nobel, 1988. 121 p.

VILLARREAL, L. A. H. Planos de nutrição influenciando as características de carcaça de suíno de dois genótipos com diferentes pesos ao abate. 1996. $73 \mathrm{f}$. Dissertação (Mestrado em Zootecnia) - Universidade Federal de Lavras, Lavras, 1996.

WOOD, J. D. Consequences for meat quality of reducing carcass fatness. In: WOOD, J. D.; FISHER, A. V. (Eds.)

Reducing fat in meat animals. London: Elsevier, 1990. p. 344-389. 